University of Nebraska - Lincoln

DigitalCommons@University of Nebraska - Lincoln

Publications, Agencies and Staff of the U.S.

Department of Commerce

U.S. Department of Commerce

3-2007

\title{
A Biological Framework for Evaluating Whether a Species Is Threatened or Endangered in a Significant Portion of Its Range
}

Robin Waples

NOAA, robin.waples@noaa.gov

Peter B. Adams

Southwest Fisheries Science Center, pete.adams@noaa.gov

James Bohnsack

Southwest Fisheries Science Center, Jim.Bohnsack@noaa.gov

Barbara L. Taylor

Southwest Fisheries Science Center, barbara.taylor@noaa.gov

Follow this and additional works at: https://digitalcommons.unl.edu/usdeptcommercepub

Waples, Robin; Adams, Peter B.; Bohnsack, James; and Taylor, Barbara L., "A Biological Framework for Evaluating Whether a Species Is Threatened or Endangered in a Significant Portion of Its Range" (2007). Publications, Agencies and Staff of the U.S. Department of Commerce. 436.

https://digitalcommons.unl.edu/usdeptcommercepub/436

This Article is brought to you for free and open access by the U.S. Department of Commerce at DigitalCommons@University of Nebraska - Lincoln. It has been accepted for inclusion in Publications, Agencies and Staff of the U.S. Department of Commerce by an authorized administrator of DigitalCommons@University of Nebraska - Lincoln. 


\title{
A Biological Framework for Evaluating Whether a Species Is Threatened or Endangered in a Significant Portion of Its Range
}

\author{
ROBIN S. WAPLES, ${ }^{*}$ PETER B. ADAMS $†$ JAMES BOHNSACK, $\ddagger$ AND BARBARA L. TAYLOR $\S$ \\ *Northwest Fisheries Science Center, 2725 Montlake Boulevard East, Seattle, WA 98112, U.S.A., email robin.waples@noaa.gov \\ †Southwest Fisheries Science Center, 110 Shaffer Road, Santa Cruz, CA 95060, U.S.A. \\ ¥Southeast Fisheries Science Center, 75 Virginia Beach Drive, Miami, FL 33149, U.S.A. \\ $\S$ Southwest Fisheries Science Center, 8604 La Jolla Shores Drive, La Jolla, CA 92037, U.S.A.
}

\begin{abstract}
Under the U.S. Endangered Species Act (ESA), a species can be listed if it is at risk "in all or a significant portion of its range," but the ESA provides no guidance on bow to interpret this key phrase. We propose a simple test to determine whether the areas of a species' range in which it is currently at risk amount to a significant portion: If the species were to become extirpated from these areas, at that point would the entire species be at risk? If so, then these areas represent a significant portion of the species' range. By establishing the species itself as the point of reference for determining significance, this test directs attention to biological risk factors and avoids difficulties inberent in subjective evaluations of importance to bumans. For broadly distributed species this framework could provide ESA protection due to cumulative risks before the entire species met the criteria to be considered threatened or endangered. This framework also allows a somewhat broader concept of range to include major components of diversity necessary for long-term persistence. The concept of a bistorical template (i.e., conditions under which the species was known to be viable) is important in providing a fixed reference point for evaluating viability. Empirical examples illustrate bow these concepts bave been applied in recent ESA listing determinations. Most ESA-listed units of Pacific salmon (Oncorhynchus spp.) can be divided into multiple strata that differ in terms of ecology, geology, or life-bistory traits of the component populations. The goal of ESA recovery planning is to restore viable populations in enough strata that the listed unit as a whole is no longer threatened or endangered in all or a significant portion of its range. In a recent review of Pacific berring (Clupea pallasii) in Puget Sound, current status (some populations increasing and others declining) was evaluated in the context of the bistorical template, and it was concluded that current patterns of distribution and abundance do not depart substantially from what would be expected at any point in time under natural conditions in a large metapopulation. The Canadian lynx (Lynx canadensis) is ESA listed in the contiguous United States, where it occurs in four geographic areas. Populations in one region, the Northern Rockies/Cascades, have always been the most important for long-term persistence of the species in the United States. Because the other regions never contained more than limited amounts of good-quality lynx habitat, those areas are not considered to represent a significant portion of the species' range.
\end{abstract}

Keywords: Canadian lynx, Endangered Species Act, extinction risk, metapopulation, normative dimension, Pacific herring, Pacific salmon, species range

Un Marco Biológico para Evaluar si una Especie está Amenazada o En Peligro en una Porción Significativa de su Distribución

Resumen: En el Acta de Especies en Peligro (AEP), una especie puede ser enlistada si está en riesgo "en toda o una porción significativa de su distribución," pero el AEP no proporciona directrices sobre como interpretar esta frase clave, Proponemos una prueba simple para determinar si las áreas en que se distribuye

Paper submitted January 4, 2007; revised manuscript accepted March 29, 2007.

964 
una especie en riesgo son una porción significativa de su distribución total. Si la especie llegara a ser extirpada de esas áreas, ¿en que punto estaría la especie entera en riesgo? Si es así, entonces, estas áreas representan una porción significativa de la distribución de la especie. Al establecer a la especie como el punto de referencia para determinar la significancia, esta prueba dirige atención a los factores de riesgo biológico y evita dificultades inberentes a evaluaciones subjetivas de importancia para bumanos. Para especies de amplia distribución, este marco de referencia podría proporcionar protección AEP debido a riesgos acumulativos antes de que la especie entera cumpla los criterios para ser considerada amenazada o en peligro. Este marco también permite un concepto más amplio de distribución al incluir componentes mayores de la diversidad necesarios para la persistencia a largo plazo, El concepto de un templete bistórico (i.e., condiciones bajo las cuales se sabía que una especie era viable) es importante para proporcionar un punto de referencia fijo para evaluar la viabilidad. Ejemplos empíricos ilustran como se han aplicado estos conceptos en determinaciones recientes de AEP. La mayoría de las unidades de salmón del Pacífico (Oncorhynchus spp.) enlistadas en el AEP se pueden dividir en estratos múltiples que difieren en términos de características ecológicas, geológicas o de bistoria natural de las poblaciones que las componen. La meta de la planificación de recuperación del AEP es la restauración de poblaciones viables en suficientes estratos para que toda la unidad enlistada ya no esté amenazada o en riesgo en toda o una porción significativa de su distribución. En una revisión reciente de arenque del Pacífico (Clupea pallasii) en Puget Sound, el estatus actual (incremento de algunas poblaciones y decremento de otras) fue evaluado en el contexto del templete bistórico, y se concluyó que los patrones de distribución y abundancia actuales no son sustancialmente distintos de lo que se esperaría en cualquier punto en el tiempo bajo condiciones naturales en una metapoblación grande. El lince Canadiense (Lynx canadensis) esta enlistado en el AEP en E.U.A., donde ocurre en cuatro regiones geográficas. Las poblaciones en una región, Northern Rockies/Cascades, siempre han sido las más importantes para la persistencia de la especie a largo plazo en E. U. A. Debido a que las otras regiones nunca contuvieron más que cantidades limitadas de bábitat de buena calidad para linces, se considera que estas áreas no representan una porción significativa de la distribución de la especie.

Palabras Clave: acta de especie en peligro, arenque del Pacífico, dimensión normativa, distribución de la especie, Lynx canadensis, metapoblación, riesgo de extinción, Salmón del Pacífico

\section{Introduction}

Applied conservation routinely involves consideration of both scientific and normative factors. For example, assessing the likely consequences to natural systems of a particular anthropogenic action is primarily a scientific enterprise (albeit often a complex and challenging one). In contrast, determining whether these consequences are acceptable, or determining what should be done in response to the scientific conclusions, is largely a normative exercise because it involves consideration of societal values. The interface of scientific and normative processes is nowhere as evident as in the U.S. Endangered Species Act (ESA), which is arguably the most powerful environmental law in the world. Under the ESA, listing determinations must be based "solely on the basis of the best scientific and commercial data available" (ESA Sec. $4[\mathrm{~b}][1][\mathrm{A}]$ ), which places the act squarely on a scientific foundation. Yet these same listing determinations require consideration of nonscientific terms embedded in the definitions of endangered species ("in danger of extinction throughout all or a significant portion of its range") and threatened species ("likely to become an endangered species within the foreseeable future throughout all or a significant portion of its range") (emphasis added). The terms in italics are not defined in the ESA or any related policy documents produced by the U.S. Fish and Wildlife Service (USFWS) or the U.S. National Marine Fisheries Service (NMFS), the two federal agencies charged with implementing the ESA. It is broadly recognized that decisions about how severe and imminent threats must be before they are unacceptable cannot be made by science alone.

The phrase "a significant portion of its range" (hereafter, SPOIR for short), which played only a minor role in early ESA listings, has recently attracted considerable legal attention (reviewed by USFWS 2007). Vucetich et al. (2006) suggest that the SPOIR language should be interpreted in a largely normative framework. Although we agree with Vucetich et al. that the meaning of significant can be subjective and context dependent, we nevertheless believe that evaluation of this apparently normative language can be made a largely scientific exercise. This can be accomplished by removing the subjective, human dimension from the word significant. Admittedly, different individuals will attach different levels of significance to the same empirical facts. If, however, the point of reference for significance is established as the species itself, rather than its importance to humans, it becomes possible to think of a strictly biological interpretation. The SPOIR language occurs in the definition of threatened and endangered species, so it is logical that one should consider how significant the portions of range are to the species itself. Because the ESA is primarily about avoiding species' extinctions and because the definitions of threatened and 
endangered relate directly to risk of extinction, we were led to consider how significant these areas are to the risk of extinction of the entire species.

The above considerations suggest a biological definition of SPOIR and a conceptually simple test that can be applied to determine whether the areas in which a species is currently at risk constitute a "significant portion" of its range. We propose that the phrase significant portion of the range of an ESA species be defined as a geographic area(s) that contains a population unit(s) that, if lost, would cause the entire species to be in danger of extinction or likely to become so in the foreseeable future. This definition can be formulated as an operational test: If the species were to become extirpated from all areas in which it is currently at risk, at that point would the entire species be at risk of extinction (or likely to become so)? If so, then these areas represent a significant portion of the species' range.

Although conceptually simple, this test can be challenging to apply in practice. To facilitate practical application, we examined several factors that should be considered in SPOIR evaluations, applied the test to hypothetical and empirical examples, and compared our approach to the Vucetich et al. (2006) approach.

\section{A Biological Framework for Considering SPOIR}

\section{Definitions and Assumptions}

The ESA defines a "species" to include not only taxonomic species, but also subspecies and (for vertebrates only) "distinct population segments" (DPSs) (USFWS \& NMFS 1996). Each of these entities can be considered an ESA species and be listed if threatened or endangered. Here we assumed that (1) the subspecies and DPS issues have been resolved and the unit under consideration cannot be subdivided into additional ESA species and that (2) the SPOIR language applies equally to all ESA species, whether they represent taxonomic species, subspecies, or DPSs. When we use the term species, we refer to the ESA species under consideration.

We also assumed that the species in question is not in danger of extinction througbout all of its range or likely to become so in the foreseeable future; if either were true, the entire species would meet the statutory definition for listing and it would not be necessary to consider the SPOIR language. The scenarios of interest, therefore, involve an ESA species that is currently at risk in some, but not all, of its range. At least one judge has found the SPOIR language "puzzling" and "enigmatic" (Defenders of Wildlife $v$. Norton, 258 F.3d 1136, 1141; 9th Cir. 2001) because it requires consideration of partial extinctions-a term normally considered to apply to an entire taxonomic unit. We assumed that the phrase "in danger of extinction" in a SPOIR refers to local extinctions (i.e., extirpations) that might have important consequences for the entire species.

\section{Time Horizons}

Although the proposed framework removes the normative dimension from the SPOIR language itself, the definitions of threatened and endangered species still involve the normative terms in danger of, likely, and witbin the foreseeable future. These terms imply the concepts of probability (that an event will occur) and time (during which the event might occur), but neither concept is uniquely defined biologically by these terms. (See DeMaster et al. [2004] for a discussion of the scientific and policy considerations involved in interpreting this language.) For the sake of this discussion, we refer to the time horizon that corresponds to "in danger of" as $x$ years or generations and the time horizon that corresponds to foreseeable future as $y$ years or generations. In an ESA listing determination, therefore, the total time horizon for considering risks of extinction of an entire "species" is ( $x$ $+y$ ) years/generations. For example, if $x=100$ and $y$ $=30$, the total time horizon is $100+30=130$ years. That is, a species just qualifying as threatened would be likely to become endangered within 30 years, at which point it would be in danger of extinction within 100 years (Fig. 1). We refer to this combined time frame $(x+y$ years or generations) as the short-term time horizon.

In the proposed framework, risks to the species in areas that might correspond to a SPOIR also occur under this short-term time horizon (i.e., in these areas the species is either in danger of extinction/extirpation or likely to become so in the foreseeable future). Nevertheless, the threats that extirpation in the SPOIR areas would pose to

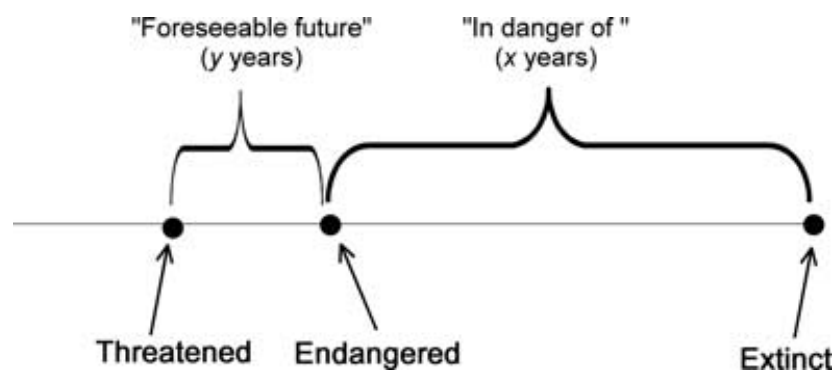

Figure 1. Diagram of time frames for risk analysis implied by the normative language in the U.S. Endangered Species Act. A species can be considered endangered at the point in time at which it is "in danger of" extinction within x years. A species can be considered threatened at the point in time at which, within the foreseeable future (indicated bere by $\mathrm{y}$ years), it is "likely" to become in danger of extinction. The total short-term time borizon for listing determinations is thus $\mathrm{x}+\mathrm{y}$ years. The specific (and relative) values of $\mathrm{x}$ and $\mathrm{y}$ are not uniquely specified biologically and require policy input. 
the species as a whole will generally occur on longer time frames. We refer to this as a long-term horizon for risk.

\section{Three Scenarios That Could Trigger a Listing Under SPOIR}

Under the proposed framework, a listing under SPOIR can occur when the affected areas are important enough to the viability of the species as a whole that their loss would place the entire species at risk. Below (and in Figs. $2 \mathrm{a}-\mathrm{c})$ we outline three general scenarios that could lead to this result.

\section{Scenario A: a Continuously Distributed Species}

Some species are more or less continuously distributed and can be thought of as approximating a single, global population (Fig. 2a). These species often have core areas of high-quality habitats that are regularly occupied and that support the bulk of the population and peripheral habitats that might be less stable or of lower quality and might be occupied only sporadically or opportunistically. Such a species typically can withstand loss of some habitat and some reductions in abundance without placing the entire species at risk. Nevertheless, if habitat loss is extensive, especially in core areas, remaining enclaves become isolated and fragmented, and demographic and population dynamic processes within the species can be disrupted to the extent that the entire species is at risk of extinction. This has occurred with the Northern Spotted Owl (Strix occidentalis caurina) and the Red-cockaded Woodpecker (Picoides borealis), both currently listed as endangered by the USFWS. Although current threats to these species are so pervasive that SPOIR considerations are moot, it seems likely that at some point in the past, habitat loss and population fragmentation would have created a level of risk that met our proposed SPOIR criteria before the entire species became threatened or endangered.

Consider another hypothetical example. Assume that species 1 historically had a core range but also periodically occupied peripheral areas on an interim basis (e.g., seasonally or for periods up to a few generations). The peripheral areas never were self-sustaining over long time periods. Currently, the species is relatively healthy in the core areas but has disappeared from or is at risk in many of the peripheral areas. This example would not generally meet the SPOIR test if the peripheral areas never were integral to long-term persistence of the species, even if collectively they represent a relatively large geographic area. For a recent empirical example of this scenario, see the discussion below of a recent decision by the USFWS (2007) regarding U.S. populations of the Canadian lynx (Lynx canadensis). Nevertheless, this scenario could trigger a SPOIR concern under certain circumstances. Even if (on average) they acted as population sinks, the pe-

ripheral areas collectively might have played an important role historically in ensuring long-term viability of the species as a whole. Long-term persistence of a source-sink system can depend on an adequate number of population sinks, even if their mean net productivity is negative

\section{At risk of extinction/extirpation \\ Likely to become endangered \\ Extirpated/extinct}

Core habitat

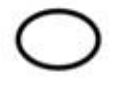

Peripheral habitat

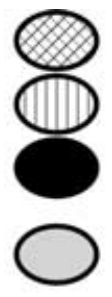

(a) Continuous distribution

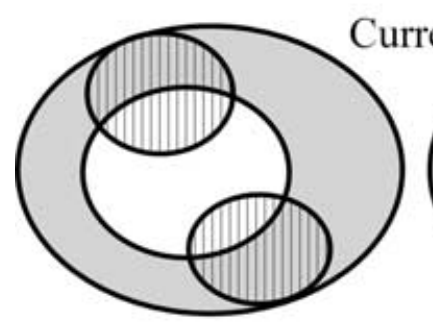

Threatened under SPOIR

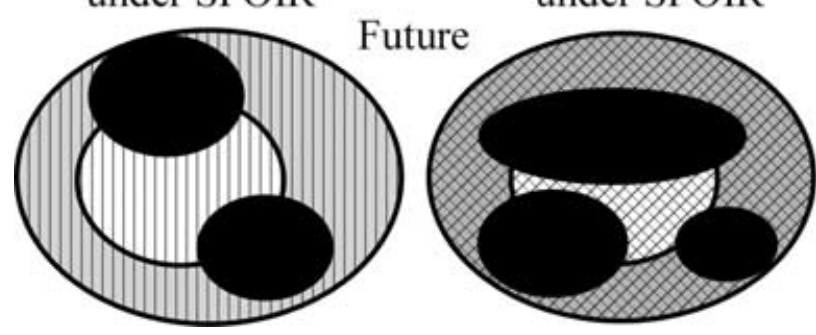

Figure 2. Three scenarios in which a species is currently at risk in a significant portion (but not all) of its range (SPOIR). Current risks (top panels) occur within the normal ESA time borizon ( $\mathrm{x}+\mathrm{y}$ years; Fig. 1), and extirpation in these portions of its range would place the entire species at risk in the future (bottom panels). (a) Single, global population: In the example on the right, the areas where the species is currently at risk are substantial enough that extirpation would place the entire species in danger of extinction. In the example on the left, the areas where the species is at risk are less extensive, and extirpation in these areas would make the entire species likely to become endangered in the foreseeable future. (b) Loss of key metapopulation components (subpopulations and processes of connectivity) can place the entire species at risk. (c) Intraspecific biocomplexity (ecological, bebavioral, life bistory, genetic; indicated by different shapes) is important to resilience and long-term viability of the species. 
(b) Metapopulation
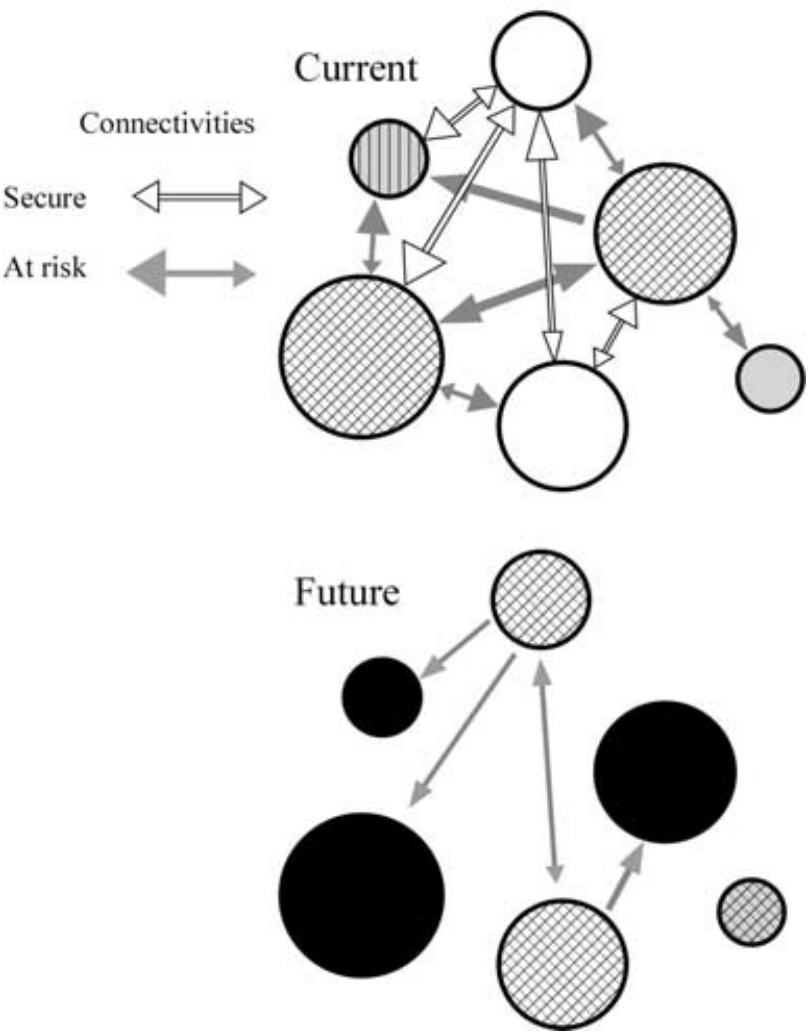

(c) Biocomplexity

\section{Current}

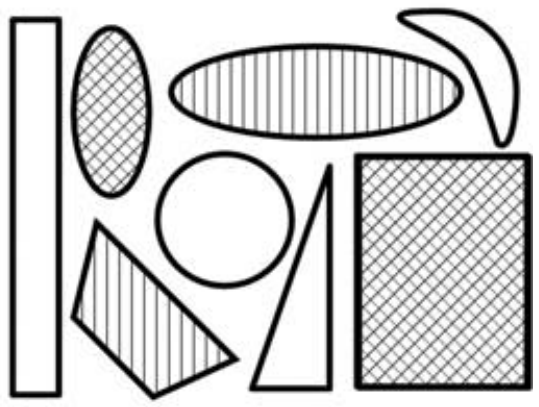

\section{Future}
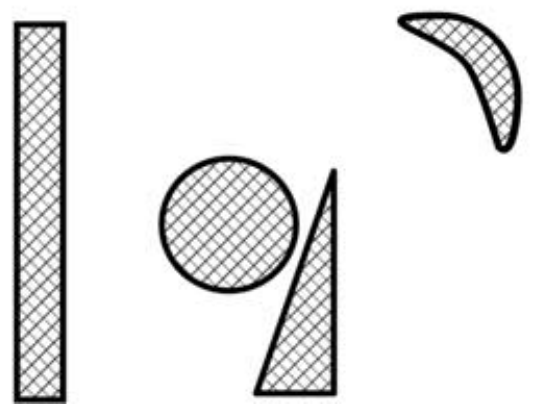

Figure 2. (continued)
(Hanski \& Gaggiotti 2004). These areas function to spread risk when environmental conditions change such that the core source area becomes temporarily less suitable for the species.

\section{Scenario B: a Metapopulation}

Many species have a metapopulation structure and exist as a collection of interacting populations. Disruption of patterns of dispersal, gene flow, and connectivity, together with short-term threats to affected areas, can impede basic biological processes necessary for the species' survival (Fig. 2b).

To illustrate, assume that species 2 historically acted like a classical metapopulation, with extirpation and recolonization of local populations occurring regularly on ecological time frames. Under these circumstances, a status assessment conducted at a single point in time might find that some habitat patches are occupied by stable populations, some are decreasing in size or unoccupied, and others (following recent recolonization) support recovering populations. An assessment taken at another point in time might find the same general pattern, but the status of individual populations might have changed.

This example illustrates the importance of understanding the historical template. If the species has persisted as a metapopulation under historical conditions, then finding a mosaic pattern of population health at any point in time should not in itself be cause for concern. This could be true even if the areas that appear to be at risk collectively represent a substantial geographic area. The key is whether departures from the historical template are important to the species' persistence. The following are two examples of patterns of decline that are particularly worrisome and could meet our SPOIR criteria.

1. The areas of local extirpation or decline are substantially more pervasive than they were historically during typical "down" cycles.

2. A pattern of permanent or long-lasting habitat destruction renders areas unable to support viable populations in the future. A metapopulation depends on recolonization of vacant habitat patches at a rate that matches the rate of local population extirpation. If some areas are precluded from recolonization and local recovery, the system as a whole could decay until it is no longer stable. Therefore, pervasive threats (such as habitat loss or fragmentation, blockage of migratory routes) that threaten to disrupt fundamental metapopulation processes can constitute risk to a significant portion of a species' range.

Scenarios A and B are obviously related and are provided only as illustrations of two generic types of population structure along the continuum from completely random mating to extreme isolation. 


\section{Scenario C: Diversity}

In the simplest forms of scenarios A and B, habitats might differ in quality and size, but individuals in different habitat patches can be considered demographically exchangeable. Nevertheless, many species exhibit considerable heterogeneity among populations in ecological, behavioral, physiological, life-history, and genetic characteristics. This diversity is generally believed to buffer a species against environmental fluctuations in the short term and to provide evolutionary resilience to meet future environmental changes (e.g., Hilborn et al. 2003). Scenario C involves the loss (extinction) of genetically based traits that represent major components of diversity within the species. Loss of sufficient diversity could place the entire species at long-term risk of extinction, and from this perspective it might be concluded that the diversity components that are currently at risk represent a significant portion of the species' range (Fig. 2c). Loss of diversity also constrains evolutionary potential and can place the species on a dramatically different evolutionary trajectory. Therefore, threats in a SPOIR can disrupt evolutionary processes within the species to the extent that its future evolutionary trajectory is dramatically changed, and it might no longer be recognizable as the same ESA species.

Consider hypothetical species 3 , which historically existed as a collection of demographically independent breeding populations. The species also undertakes long-distance migrations, so historical genetic exchange among local populations occurred often enough to keep the populations linked together as a unit following a common evolutionary trajectory. Recent anthropogenic events make it difficult or impossible for the species to complete its historical migrations, resulting in fragmentation and isolation of local populations.

This situation could meet our proposed SPOIR criteria under scenario $\mathrm{C}$. Although at least some of the local populations might be able to persist in a nonmigratory form, the natural life cycle of the species would be substantially altered. If selection against the migratory tendency is strong enough over a long enough time period, the genetic architecture capable of producing successful migration could be lost from the species. Furthermore, in this situation migration provides the evolutionary glue that holds the species together as a biological entity. Loss of this function would shift the species to a very different evolutionary trajectory than was created under the historical template. Migration among populations is also integral to Wright's (1931) shifting-balance theory of evolution, and impairing this function can limit the ability of a species to adapt to future change.

\section{Empirical Examples}

To complement these hypothetical examples, we provide three examples of applied conservation in which princi- ples outlined in the proposed SPOIR approach have been implemented under the ESA.

\section{Pacific Salmon Recovery}

The NMFS uses the concept of evolutionarily significant units (ESUs) to identify DPSs of Pacific salmon (Oncorbynchus spp.). On the west coast of the United States, over 20 ESUs/DPSs of Pacific salmon are ESA listed, and most include multiple populations or stocks that are demographically independent. To provide a biological framework for salmon recovery planning under the ESA, NMFS scientists developed the concept of "viable salmonid populations" (VSP) (McElhany et al. 2000). Viability is assessed first at the population level according to the four VSP criteria (abundance, productivity, spatial structure, and diversity). Next, criteria are developed to determine which and how many populations must be at what level of health before the entire ESU can be delisted.

A common practice of the different salmon-recovery teams has been to divide the ESUs into "strata" and require at least some healthy populations in each stratum (documents available at http://www.nwfsc.noaa.gov/trt/ index.cfm). Typically, the strata represent geographic areas within the ESU that differ in terms of, for example, geology and ecology. Some strata also reflect patterns of life-history diversity (e.g., spring-run vs. fall-run Chinook salmon). Requiring healthy populations across multiple strata is the best way to meet the diversity and spatialstructure criteria for the ESU as a whole. These strata typically have strong geographic components but are not limited exclusively to the concept of geographically contiguous areas. Restoration of viable populations in multiple strata provides evidence that the species is no longer threatened or endangered in all or a SPOIR.

\section{Puget Sound Herring}

For a recent evaluation by NMFS of a series of ESA petitions to list Pacific herring (Clupea pallasii) in Puget Sound, it was necessary to consider how the concept of metapopulations (scenario B) relates to ESA risk analysis. Both Pacific and Atlantic herring (C. harengus) have numerous spawning aggregations that appear to act as classical metapopulations in which local extinction and recolonizations are common and a relatively high flux of individuals among spawning sites occurs (McQuinn 1997; Ware \& Tovey 2004). Some Puget Sound populations of Pacific herring are increasing, while others are depressed or perhaps extirpated. The NMFS Biological Review Team (team) first determined that Puget Sound herring are part of a DPS that includes populations in the Strait of Georgia and the Strait of Juan de Fuca (Gustafson et al. 2006), and then they considered whether the DPS was threatened or endangered in all or a SPOIR. The team evaluated the current status in the context of the historical template and concluded that current patterns of distribution and 
abundance do not depart substantially from what would be expected at any given point in time under "natural" conditions. Consequently, the team concluded that the DPS that contains Puget Sound herring is not in danger of extinction (or likely to become so) in a SPOIR. Nevertheless, the team noted that some of the more distinctive populations are currently depressed and outlined some potential future scenarios that could lead to substantially higher risk to the DPS (Gustafson et al. 2006).

\section{Canadian Lynx}

The USFWS recently clarified (USFWS 2007) how it has considered whether Canadian lynx in the United States are at risk in a significant portion of their range. They first determined that lynx populations in the contiguous United States collectively are a DPS of the global species, but that none of the geographic populations within the United States (Northeast, Great Lakes, Southern Rockies, and Northern Rockies/Cascades) is a DPS by itself. The USFWS then evaluated population status within each of these geographic regions and, collectively, how these threats related to the SPOIR language. They concluded that the Northern Rockies/Cascades region was "the primary region necessary to support the long-term existence of the contiguous U.S. DPS" and that, both historically and at present, the other geographic areas contained only limited amounts of good-quality lynx habitat (USFWS 2007). Accordingly, the USFWS concluded that these other areas do not constitute a significant portion of the range of the DPS. In making this determination the USFWS referred to the historical template and emphasized their interpretation that a significant portion of a species' range most appropriately refers to a biologically important portion, not just a geographically large portion.

\section{Discussion}

Many species experience a cumulative loss of range to the point that eventual extinction is likely unless conditions are reversed. Nevertheless, such species might not face serious extinction risk throughout their range before their status declines to a point at which recovery is difficult and conservation measures expensive and of uncertain utility. The significant portion of the range language in the ESA allows a more proactive intervention that minimizes the number of species needing emergency treatment while focusing only on species for which overall biological threats are substantial. In this respect the SPOIR language reflects foresight on the part of framers of the ESA in anticipating just how important spatial structure and biocomplexity have become to the fields of ecology and evolutionary biology.
In our SPOIR framework, the areas at risk threaten to disrupt fundamental biological processes necessary for long-term persistence and viability of ESA species. The consequences of these threats can be quite predictable, at least in a general way, but their principal effects on absolute extinction risk of the entire species probably occur on longer time frames than are typically considered in evaluating ESA extinction risk. Although our proposed test is simple in concept, it will be challenging to apply in practice because understanding of how complex biological systems work is imperfect. These challenges, however, pertain to any attempt to apply biological principles to such systems and do not preclude successful practical applications. It is not necessary to have detailed biological information for the species to apply the conceptual framework we propose. Indeed, critical information gaps exist for most, if not all, species under the stewardship of the USFWS and NMFS. Therefore, lack of a specific type(s) of information should not preclude application of this biologically based framework to SPOIR determinations. In general, application of the proposed SPOIR framework should be no more difficult than the identification of DPSs that have been carried out by FWS and NMFS over the past decade based on their joint DPS policy (USFWS \& NMFS 1996).

In our framework threats to the species in the SPOIR areas occur on the same short-term $(x+y$ years) time horizon of typical ESA evaluations, but the key question then becomes, What happens next? It might seem that the proposed framework thus extends the time horizons for considering threatened and endangered status beyond those contemplated by the ESA. Nevertheless, the SPOIR language in the ESA seems to imply that these additional considerations are necessary. If the threats apply to the entire species within the short-term time horizon, then the SPOIR language is not relevant. The SPOIR language thus implies that factors must be considered prior to the time during which the entire species is threatened or endangered.

\section{The Meaning of Range}

In scenarios A and B the concept of range has a direct geographic context, representing either one or a few substantial geographic areas or several smaller areas that collectively encompass a significant geographic range (Figs. 2a \& 2b). Scenario C implies a somewhat broader interpretation of range to include the natural range of phenotypes, behaviors, and life-history traits that collectively characterize the ESA species under consideration. If these traits are genetically based, then their loss could represent extinction of a significant portion of the range of characteristics expressed by the species. Usually these traits can be associated with local subpopulations or areas, which 
establishes a link with the strictly geographic concept of range.

\section{Historical Template}

A useful reference point for SPOIR evaluations is the historical template, which describes historical patterns of distribution and abundance and the range of, for example, behavioral, life-history, and genetic traits of the species. Species are not threatened or endangered simply because their status departs from the historical template; some might be viable with substantial reductions compared with historical conditions. In addition, evolution is a dynamic process, so it is not always easy to determine the appropriate time frame for "historical" population conditions. Moreover, because (within certain limits) species are capable of adapting and responding to changing environmental conditions over time, the historical template is not necessarily static. Nevertheless, this concept is important to consider because the historical template is the only one known to be capable of ensuring long-term viability of the species in nature. The more current conditions depart from the historical template, the greater uncertainty there is that the species will remain viable into the future. Without a fixed historical reference point, risk assessments can be overly optimistic because of the shifting baseline syndrome (Pauly 1995). If current conditions are substantially different than the historical template, it becomes increasingly important to document and test reasons for believing that the species can be viable in the future under the compromised conditions. Conversely, if current conditions roughly approximate the historical template, then absent compelling evidence to suggest otherwise, it can generally be concluded that the species is not at significant short-term risk.

It is particularly useful to compare the geographic range over which the species is viable today with the range over which it was viable historically. If the former is much smaller, the areas in which the species is at risk could represent a significant portion of the range, even though the species is currently viable in selected localities. Considerations in this context include whether the affected areas include some of the best habitat for the species and whether the species has been pushed into areas of marginal habitat, thus adding to long-term threats. In evaluating these situations, the fundamental question is what effect declines in the other areas have on longterm prospects for survival in the remaining (currently viable) areas.

\section{Connectivity, Diversity, Resiliency}

Species are coherent demographic/genetic units connected (at least periodically) by exchanges of individuals and their genes. In many species biocomplexity plays an important role in providing resiliency. Major disruptions to these processes can threaten long-term viability of the species as a whole. In evaluating whether areas where species are currently at risk meet the proposed SPOIR test, it is important to consider questions such as how resilient is the species in the areas in which it is currently considered viable? Has productivity been compromised? What is the species' ability to recover from periodic disturbances or environmental variability? How does current status compare with the historical template in the range of genetically based traits? Has a substantial range of historical traits been lost, or is a substantial fraction of these traits at significant short-term risk? Would loss of this genetically based diversity substantially reduce the ability of the species to respond and adapt to future environmental changes or perturbations? These questions should be considered in the context of habitat quality and quantity because a species is typically most resilient in its best habitat.

\section{"Significance" in SPOIR and DPS Considerations}

The NMFS salmon ESU policy (NMFS 1991) and the joint interagency DPS policy (USFWS \& NMFS 1996) both include a "significance" test as one criterion for being considered a DPS. Notably, both policies evaluate significance with respect to the species itself. In the salmon ESU policy, the criterion is "evolutionary significance," which implies genetic resources that are important to the species as a whole (Waples 1991, 1995). In the joint DPS policy, the criterion is "significance to the taxon to which it belongs," and among the types of evidence that can be considered are occurrence of the species in an unusual ecological setting and marked differences in genetic traits (USFWS \& NMFS 1996).

In our proposed SPOIR approach significance is also evaluated with respect to the species itself, but there are some important differences between the SPOIR and DPS evaluations. In the latter the goal is to define the ESA species, and significance is evaluated with respect to a larger "taxon" (named species or subspecies). In contrast, SPOIR evaluations only occur after the ESA species has been identified, and the point of reference is not the higher-level taxon but rather the ESA species itself, which can be a DPS. Second, whereas DPS considerations focus on ecological and evolutionary significance, the proposed SPOIR framework focuses directly on significance to extinction risk. This focus seems appropriate, given that the SPOIR language is found in the statutory definitions of threatened and endangered species. Finally, in both DPS policies the significance criterion is paired with a criterion for isolation or discreteness, which leads to consideration of cohesive units that share a common ecological or evolutionary trajectory. In contrast, a significant portion of the range of a species might represent a number of areas that are not demographically or genetically coherent but that collectively have a significant effect on the species' extinction risk. 
An example illustrates the distinction. Consider a scenario-A species in which none of the local populations are particularly discrete or distinctive, and therefore there are no DPSs. At some point, however, loss of a critical mass of the areas will place the entire species at risk. These areas could be considered to constitute a significant portion of the range of the species, even though none individually is significant enough to be a DPS.

\section{Endangered under SPOIR}

Our proposed framework, in which extirpation of a species from portions of its range could place the entire species at risk in the future, is generally congruent with the ESA concept of a threatened species; the only difference is the time frame under consideration. The concept of a species that is endangered in a SPOIR is trickier to evaluate and merits some discussion. If a species is currently in danger of extinction (E) in a portion, but not all, of its range, its ESA status in the remainder of its range can be characterized as either likely to become endangered in the foreseeable future ( $\mathrm{T}$ ) or neither $\mathrm{T}$ nor $\mathrm{E}$. Under our SPOIR framework, we consider how extirpation of the species from the E portion of its range would affect its overall status in the future, leading to the five scenarios shown in Table 1. If extirpation would not affect future viability of the species as a whole (scenario I), our framework would not lead to a listing under SPOIR. Conversely, if the species is currently $\mathrm{T}$ in the rest of its range (scenarios IV and V), the entire species can be listed without resorting to the SPOIR language.

Scenarios II and III satisfy our proposed criteria for a listing under SPOIR, but what should the listing status be? In scenario II a future extirpation places the rest of the species at $\mathrm{T}$ risk, whereas in scenario III the extirpation places the rest of the species at E risk (the top right panel in Fig. 2a depicts scenario III). Would both scenarios lead to the same listing status, and if so, would it be $\mathrm{T}$ or $\mathrm{E}$ ? Or is it possible to assign different listing status to different portions of a species' range under SPOIR? Answering these questions involves legal and policy issues that are beyond the scope of this paper. We can, however, clarify some biological issues that could help inform the legal and policy considerations. First, it is possible (perhaps even likely) for a species to experience different magnitudes of threat and to manifest different degrees of population viability in different portions of its range. Furthermore, current status and threats in certain populations can affect future viability of the species as a whole. Second, the five scenarios are associated with different levels of risk to the species as a whole, both currently and in the future (Table 1). To maximize conservation benefits, ESA protections should be commensurate with relative risks. This would suggest, for example, that any SPOIR listing involving a species that is currently $\mathrm{E}$ in a portion of its range should not result in a more extreme listing status than would scenario V, which entails the highest combined overall risk to the species. In other words, if scenarios II or III resulted in the entire species being listed as $\mathrm{E}$, whereas scenarios IV or V resulted in the entire species being listed as $\mathrm{T}$, the listings would not be commensurate with the species' relative risks.

\section{An Alternative Framework for Considering SPOIR}

In a recent essay that discussed the SPOIR language, Vucetich et al. (2006) noted that (1) ESA listing determinations involve both scientific and normative determinations; (2) a general correlation exists between extinction risk and geographic distribution; and (3) because the meaning of significant can vary depending on the context, the portion of a range that might be considered significant also can vary among species. On these points we are in agreement with Vucetich et al. (2006). Those authors also cited some legislative language and recent court cases to support their argument that the most appropriate way to approach the SPOIR language is in a normative framework, guided loosely by some general biological principles. Here we do not attempt to decipher the legislative intent behind the ESA or the import

Table 1. Five scenarios (I-V) of current and future risks possible for an ESA species that is currently at risk of extinction (E) in a portion, but not all, of its range.*

\begin{tabular}{|c|c|c|c|c|c|c|c|c|c|c|c|}
\hline & \multicolumn{2}{|c|}{$I$} & \multicolumn{2}{|c|}{ II } & \multicolumn{2}{|c|}{ III } & \multicolumn{2}{|c|}{$I V$} & \multicolumn{3}{|c|}{$V$} \\
\hline Current & $\mathrm{E}$ & $\mathrm{N}$ & $\mathrm{E}$ & $\mathrm{N}$ & $\mathrm{E}$ & $\mathrm{N}$ & $\mathrm{E}$ & $\mathrm{T}$ & $\mathrm{E}$ & & $\mathrm{T}$ \\
\hline overall risk & \multicolumn{2}{|c|}{1} & \multicolumn{2}{|c|}{1} & \multicolumn{2}{|c|}{1} & \multicolumn{2}{|c|}{2} & \multicolumn{3}{|c|}{2} \\
\hline Future & $\mathrm{X}$ & $\mathrm{N}$ & $\mathrm{X}$ & $\mathrm{T}$ & $\mathrm{X}$ & $\mathrm{E}$ & $\mathrm{X}$ & $\mathrm{T}$ & $\mathrm{X}$ & & E \\
\hline
\end{tabular}

*In the rest of its range, the species currently is either likely to become endangered (T) or neither T nor $E$ ( $N)$. Under the assumption that the species is extirpated $(X)$ from the portions of its range where it is currently at risk of extinction, future status of the species in the rest of its range can be characterized as $N, T$, or E. The relative overall risks to the species as a whole, both currently and in the future, are indicated by ordinal numbers $(3=$ highest risk). See text for discussion of the possible listing status of the species under Scenarios II to V. 
of recent court cases. Instead, we focus on three arguments by Vucetich et al. (2006) that illustrate differences between their approach and the framework we propose here.

Vucetich et al. (2006) argue that there is an inherent upper limit to what might be considered not to represent a significant portion of a range: "it is difficult ... to conceive of circumstances in which 33\% or more of a species' range could be considered insignificant." Vucetich et al. thus define those portions of a species' range that do not meet the SPOIR criteria as insignificant. This formulation is unfortunate because of the negative connotations associated with the word insignificant, which heavily color all their subsequent analyses and discussion. Portions of a range that do not meet the SPOIR test under the legal framework of the ESA are not necessarily insignificant; they just did not meet the significance test under SPOIR. Such areas still could be judged significant in other contexts, such as providing ecosystem services. Furthermore, Vucetich et al. (2006) provide little justification for the $33 \%$ rule or for choosing any particular value as a threshold for significance. It might be true, as they say, that "virtually everyone is able to discuss and understand different points on what is and what is not a significant portion of range." Nevertheless, there is no expectation that everyone will agree on what this phrase means; in fact, experience dictates the opposite is more likely. For example, we can easily envision a scenario under which, say, $40 \%$ of a species' range would not meet the SPOIR test. This could happen under scenario A: a species with robust populations in $60 \%$ of its historical range, particularly if that range included large portions of high-quality habitat, might have a low long-term risk of extinction and hence, under the framework we propose, not be considered threatened or endangered in all or a SPOIR. Conversely, a small fraction of a species' range might equate to a SPOIR if that part of the range played a crucial role in the species' viability.

The second major argument advanced by Vucetich et al. (2006) is that determinations about ESA listing and recovery should focus primarily on the SPOIR language: "The ESA largely specifies the conditions for endangerment when it defines an endangered species and a threatened species in terms of significant portion of range." The implication is that by focusing on the SPOIR language one can avoid the difficult problem of interpreting the normative terms likely, foreseeable future, and in danger of. Unfortunately, this is not the case. Even if agreement could be reached on how to interpret the SPOIR language itself, it would still be necessary to determine whether the species is "in danger of extinction" or "likely" to become so in the foreseeable future in those areas, and such determinations require consideration of the time dimensions and probabilities discussed above.

Finally, Vucetich et al. (2006) argue strenuously against relying on population viability analyses (PVAs) to guide re- covery determinations under the ESA. Although we leave it to others to respond to these points in detail (see Coulson et al. (2001) and Morris and Doak (2002) for discussions of the pros and cons of using PVAs in conservation), we disagree with the premise that consideration of viability is discretionary under the ESA. In fact, it is impossible to evaluate whether a species is in danger of extinction without considering the concept of viability. Our proposed framework makes this explicit by relating the SPOIR language directly to long-term viability of the species itself.

\section{Conclusions}

Both normative and scientific frameworks can be used to interpret the meaning of "significant portion of its range" in the U.S. Endangered Species Act. The ESA definitions of threatened and endangered species already contain normative language that requires policy decisions about permissible levels of risk and the time frames over which these risks operate, so adopting a normative framework for the SPOIR language could be seen as a natural extension of this process. Furthermore, as noted by Vucetich et al. (2006) and others (Scott et al. 2006), involving stakeholders in ESA recovery planning can have some real benefits. Nevertheless, evaluating significance with respect to human values entails some substantial drawbacks. First, in a process without any firm guidelines and in which local input can heavily influence the outcome, it will be difficult to develop any consistency or predictability in application of the SPOIR test. Second, this approach loses part of the link with the fundamental goals of the ESA: preventing extinctions. For example, Vucetich et al. (2006) propose that wolf recovery requires healthy populations in at least two-thirds of the historical range, and they acknowledge that this proposal will be unpopular with some and could require major life-style changes for many. Nevertheless, there is no meaningful analysis of what protection of this much habitat would mean to the listed species itself. Perhaps the remaining populations would be equally viable in something less than two-thirds of the historical range, or perhaps the species could not be viable without at least $80 \%$ of its historical range. The approach proposed by Vucetich et al. (2006) risks overor underprotection of the species itself, which can only be evaluated by considering the biological consequences of recovering different portions of the range.

Ours is not the only biological framework that might be developed to interpret the SPOIR language, but it has the advantage that it provides a straightforward link to the concept of extinction. It is possible to find many dictionary definitions of significant, but we believe the one cited by Vucetich et al. (2006) ("having or likely to have influence or effect"; Merriam Webster's Collegiate Dictionary 2003) captures the essence of our proposed 
approach. We propose that the portions of a species' range in which it is currently at risk are "significant" under SPOIR if extirpation in those areas would substantially influence extinction risk of the entire species.

Regardless what framework is used to interpret the SPOIR framework, ESA determinations for listing and recovery will still have to deal with the normative terms in the definitions of threatened and endangered species (in danger of, likely, foreseeable future). An advantage of our proposed approach is that it avoids additional normative considerations for the SPOIR language by evaluating significance with respect to the ESA species rather than to human values.

\section{Acknowledgments}

We are grateful to M. Nammack, D. Darm, and many others within NMFS who provided valuable suggestions and discussions on this topic and to S. Chambers, S. Haig, J. Vucetich, and an anonymous reviewer for insightful comments on an earlier draft. We thank K. Neely for help with Fig. 2. The views expressed are the authors' own and do not necessarily represent the views of the NMFS.

\section{Literature Cited}

Coulson, T.N., G. M. Mace, E. Hudson, and H. Possingham. 2001. The use and abuse of population viability analysis. Trends in Ecology \& Evolution 16:219-221.

DeMaster, D., R. Angliss, J. Cochrane, P. Mace, R. Merrick, M. Miller, S. Rumsey, B. Taylor, G. Thompson, and R. Waples. 2004. Recommendations to NOAA Fisheries: ESA listing criteria by the Quantitative Working Group. Technical memorandum NMFS-F/SPO-67. National Oceanic and Atmospheric Administration, Seattle.

Gustafson, R. G., J. Drake, M. J. Ford, J. M. Myers, E. E. Holmes, and R. S. Waples. 2006. Status review of Cherry Point Pacific herring (Clupea pallasii) and updated status review of the Georgia Basin Pacific herring distinct population segment under the Endangered Species Act. Technical memorandum NMFS-NWFSC-76. National Oceanic and Atmospheric Administration, Seattle.

Hanski, I., and O. Gaggiotti, editors. 2004. Ecology, genetics, and evolution of metapopulations. Elsevier, Amsterdam.
Hilborn, R., T. P. Quinn, D. E. Schindler, and D. E. Rogers. 2003. Biocomplexity and fisheries sustainability. Proceedings of the National Academy of Sciences, USA 100:6564-6568.

McElhany, P, M. H. Ruckelshaus, M. J. Ford, T. C. Wainwright, and E. P. Bjorkstedt. 2000. Viable salmonid populations and the recovery of evolutionarily significant units. Technical memorandum NMFSNWFSC-42. National Oceanic and Atmospheric Administration, Seattle.

McQuinn, I. H. 1997. Metapopulations and the Atlantic herring. Reviews in Fish Biology and Fisheries 7:297-329.

Morris, W. F., and D. F. Doak. 2002. Quantitative conservation biology: theory and practice of population viability analysis. Sinauer Associates, Sunderland, Massachusetts.

NMFS (National Marine Fisheries Service). 1991. Policy on applying the definition of species under the Endangered Species Act to Pacific salmon. Federal Register 56:58612.

NMFS (National Marine Fisheries Service). 2005. 12-month finding on petition to list the Cherry Point stock of Pacific herring as an endangered or threatened species. Federal Register 70:33116.

Pauly, D. 1995. Anecdotes and the shifting baseline syndrome of fisheries. Trends in Ecology \& Evolution 10:430.

Scott, J. M., D. D. Goble, and F. W. Davis, editors. 2006. The Endangered Species Act at thirty: conserving biodiversity in human-dominated landscapes. Island Press, Washington, D.C.

USFWS (U.S. Fish and Wildlife Service). 2007. Clarification of significant portion of the range for the contiguous United States Distinct population segment of the Canada Lynx. Federal Register 72:1186.

USFWS (U.S. Fish and Wildlife Service) and NMFS (National Marine Fisheries Service). 1996. Policy regarding the recognition of distinct population segments under the Endangered Species Act. Federal Register 61:4722.

Vucetich, J. A., M. P. Nelson, and M. K. Phillips. 2006. The normative dimension and legal meaning of Endangered and Recovery in the U.S. Endangered Species Act. Conservation Biology 20:13831390.

Waples, R. S. 1991. Pacific salmon, Oncorbynchus spp., and the definition of "species" under the Endangered Species Act. Marine Fisheries Review 53:11-22.

Waples, R. S. 1995. Evolutionarily significant units and the conservation of biological diversity under the Endangered Species Act. American Fisheries Society Symposium 17:8-27.

Ware, D. M., and C. Tovey. 2004. Pacific herring spawn disappearance and recolonization events. Fisheries and Oceans Canada, Ottawa. Canadian Science Advisory Secretariat, research document 2004/008. Available from http://www.dfo-mpo.gc.ca/csas/CSAS/ DocREC/2004/RES2004_008_E.pdf (accessed March 2007).

Wright, S. 1931. Evolution in Mendelian populations. Genetics 16:97159.

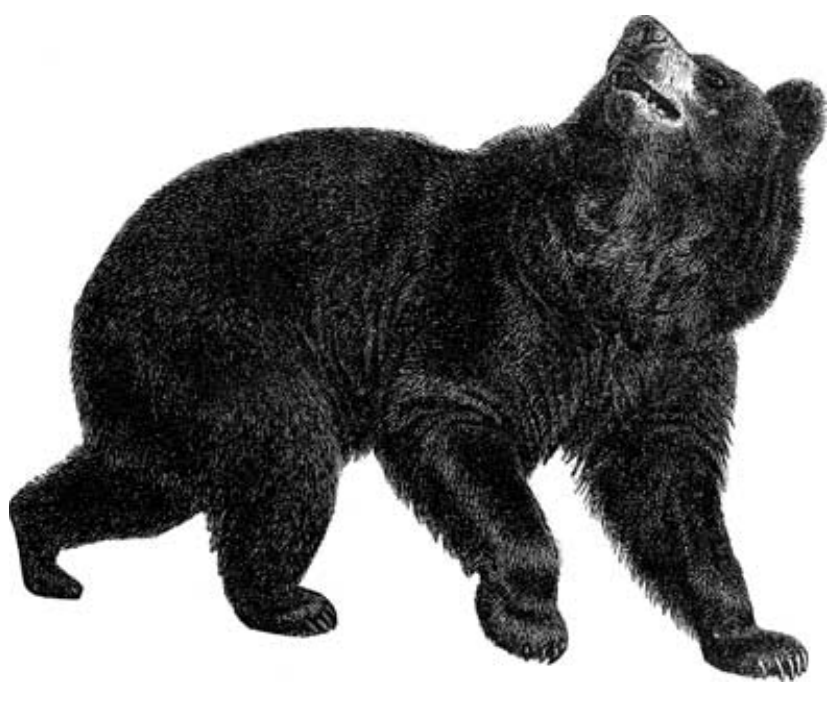

